\title{
The Adsorption and Oxidation of Isopropanol at Platinum Electrode in Alkaline Media*
}

\author{
LIN, Heng ${ }^{1}$ CHEN, Guo-Liang ${ }^{1,2}$ ZHENG, Zi-Shan ${ }^{1} \quad$ ZHOU, Jian-Zhang ${ }^{2}$ \\ CHEN, Sheng-Pei ${ }^{2} \quad$ LIN, Zhong-Hua ${ }^{2}$ \\ ('Department of Chemistry, Zhangzhou Normal College, Zhangzhou 363000; ${ }^{2}$ State Key Laboratory of Physical Chemistry of the \\ Solid Surfaces, College of Chemistry and Chemical Engineering, Xiamen University, Xiamen 361005)
}

\begin{abstract}
The adsorption and oxidation of isopropanol in alkaline media at platinum electrode have been investigated by using electrochemical quartz crystal microbalance (EQCM) and in situ FTIR spectroscopy. The results show that there is no self-poisoning in the electrooxidation of isopropanol in alkaline media. Though no poison species, such as CO, are evidenced by in situ FTIR spectroscopy, the adsorption of isopropanol or its dissociative products on Pt surface is suggested by EQCM data. The final product of isopropanol oxidation is only acetone under experimental condition, which suggests that the oxidation of isopropanol into acetone takes place via dehydrogenation step. The EQCM studies provide quantitative results of surface mass variation and have thrown new light in the elucidating isopropanol oxidation.
\end{abstract}

Keywords: Pt electrode, Electrooxidation, Isopropanol, In situ FTIR, EQCM, Alkaline media

The electrochemical oxidation of small organic molecules is of fundamental importance in electrocatalysis, and is also a key factor in the application of the oxidation as anodic process in direct fuel cells. Isopropanol is the smallest secondary alcohol molecule. Due to the particularity of the molecular structure, isopropanol is the only molecule among $\mathrm{C}_{3}$ alcohol that fails to dissociate into $\mathrm{CO}$ at the surface of platinum electrodes in acidic media $^{[-2]}$. This feature makes isopropanol suitable to be employed in fundamental studies, such as electrochemical reaction kinetics $^{[3-4]}$ and the effects of molecular structure ${ }^{[1]}$. The oxidation of isopropanol in acidic media on platinum single crystal and poly-crystalline electrode has been investigated extensively by using traditional electrochemical methods ${ }^{[5]}$, mass spectroscopy ${ }^{[7]}$, and in situ spectroscopy ${ }^{[1-4]}$.

In situ FTIR spectroscopy is a powerful tool for determining intermediates and products involved in the oxidation at molecular level ${ }^{[8]}$. Since IR spectroscopy was introduced into the field of in situ electrochemical studies, numerous experiments using this technique have been carried out. It has been applied most frequently in the investigation of electrocatalysis in fuel cell applications. It is worth pointing out that nearly all investigations mentioned above are carried out in acidic media.

In the last decade, the application of the quartz crystal microbalance (QCM) technique in an electrochemical cell, under potential control, led to the EQCM. The attractiveness of this approach is based on the high sensitivity of the quartz crystal resonator to mass change $\mathrm{e}^{[0]}$. Under favorable conditions, a typical EQCM can measure a mass change of $0.1 \sim 1 \mathrm{ng} \cdot \mathrm{cm}^{-2}$ at electrode/electrolyte interfaces, so has wide applications in the characterizations of the interfacial electrochemical processes such as the transport of ions and solvents during electrochemical reactions, detection of chemic al and biochemical species, deposition of metals on surfaces and the growth of molecular layers.

Although a direct fuel cell based on alkaline electrolyte is more promising ${ }^{[10]}$, little attention has been paid to in situ IR spectroscopic and EQCM investigations of the oxidation of small organic molecules in alkaline media because of the progressive "carbonation" of the solution as a result of $\mathrm{CO}_{2}$ retention ${ }^{[11]}$. The aim of the study is to quantitatively investigate the electrochemical oxidation mechanism of isopropanol on Pt electrode in alkaline media at molecular level via in situ FTIR and EQCM. Besides, the results are compared with those of its oxi-

Received: April 20, 2005; Revised:June 22, 2005. Correspondent:LIN, Heng(E-mail : cheng1259@263.net; Tel:0596-2591445; Fax :05962528251). ${ }^{*}$ The Project Supported by NSFC(20433040) and NSF of Fujian Province(E0310026) 
dation in acidic medium ${ }^{[1]}$ in order to elucidate the reaction mechanism of isopropanol in alkaline media.

\section{Experiments}

The in situ electrochemical FTIR experiments were carried out using a Nicolet 870 FTIR apparatus equipped with a Gopher IR source and a MCT-B detector cooled with liquid-nitrogen. The instrument was purged throughout the experiment with clean air free $\mathrm{CO}_{2}$ and $\mathrm{H}_{2} \mathrm{O}$ by a Balston 74-5301 clean air package. $\mathrm{A} \mathrm{CaF}_{2}$ disk was used as the IR window, and an IR cell of thin layer configuration between electrode and IR window was approached by pushing the electrode against the window during FTIR measurements. The incident infrared beam was aligned at about $60^{\circ}$ to the normal of electrode surface. The multi-step FTIR spectroscopy(MS-FTIRS) technique ${ }^{[12]}$ was applied for the investigation of isopropanol adsorption and oxidation, and the spectrum was reported as the relative change in reflectivity that is calculated as $\Delta R / R\left(E_{\mathrm{s}}^{i}\right)=\left[R\left(E_{\mathrm{s}}^{i}\right)-R\left(E_{\mathrm{R}}\right)\right] / R\left(E_{\mathrm{R}}\right)$, where $\Delta R / R\left(E_{\mathrm{s}}{ }^{i}\right)$ is the resulting spectrum of the $i$ th sample potential $E_{\mathrm{s}}{ }^{i}$. $R\left(E_{\mathrm{s}}{ }^{i}\right)$ is the single beam spectrum acquired at $E_{\mathrm{s}}{ }^{i}$, and $R\left(E_{\mathrm{R}}\right)$ is the single beam spectrum recorded at the reference potential $E_{\mathrm{R}}$. In the difference spectra, the positive-going bands indicate that the IR adsorption at $E_{\mathrm{R}}$ is greater than that at $E_{\mathrm{s}}$ and the negativegoing bands correspond to the greater IR absorption at $E_{\mathrm{s}}$ than that at $E_{\mathrm{R}}$. For each spectrum 400 interferograms were collected at $16 \mathrm{~cm}^{-1}$ resolution and coadded into each single-beam spectrum.

The EG\&G PARC electrochemical device consisted of a model 263A potentiostat and a model QCA917 Seiko quartz crystal analyzer ${ }^{[13]}$, both controlled by M270 software, using an microcomputer. AT-cut quartz crystals with a fundamental frequency of $10 \mathrm{MHz}$ were used as the working electrodes. Each crystal had $0.2 \mathrm{~cm}^{2}$ circular area on each side, covered by a bimetallic layer consisting of a $\mathrm{Ti}$ substrate coated with a $\mathrm{Pt}$ surface. Electrochemical measurements were made in a compartment glass with $30 \mathrm{~mL}$ capacity. The cell had a special Teflon cover with holes designed to host the auxiliary and working electrodes and the degassing tubes. The Luggin compartment was connected directly to the cell's body.

The working electrode used in IR experiments was a $\mathrm{Pt}$ disk of $c a .5 .0 \mathrm{~mm}$ diameter. It was polished with alumina powder of $1,0.3$ and $0.05 \mu \mathrm{m}$, cleaned in an ultrasonic bath, washed again with Milli-Q water. It was subjected finally to potential cycling in $0.1 \mathrm{~mol} \cdot \mathrm{L}^{-1} \mathrm{H}_{2} \mathrm{SO}_{4}$ between -0.25 and $1.2 \mathrm{~V}$ vs $\mathrm{SCE}$ at 50
$\mathrm{mV} \cdot \mathrm{s}^{-1}$ until a stable voltammogram was achieved. This potential cycling was carried out as a pretreatment (electrochemical cleaning) in both cyclic voltammetry and IR experiments. The reference electrode was a saturated calomel electrode(SCE), separated from the cell by a bridge made of a stopcock with two ends containing the solution. The counter electrode was a Pt foil with a geometric area of $1 \mathrm{~cm}^{2}$. All the glassware was cleaned before use by immersion in $\mathrm{CrO}_{3}+\mathrm{H}_{2} \mathrm{SO}_{4}$ solution, followed by thorough rinsing in Milli-Q water.

The electrolytes were prepared with $\mathrm{NaOH}$, isopropanol of analytical grade and water purified by Milli-pore's Milli-Q system. The solutions were deaerated by bubbling nitrogen gas of high purity. The experiments were carried out at around $20{ }^{\circ} \mathrm{C}$, and under atmospheric pressure.

\section{Results and Discussion}

\subsection{Cyclic voltammetric results}

Small organic molecule oxidation in acidic media at $\mathrm{Pt}$ electrode generally contains self-poisoning phenomenon ${ }^{[1]}$, i.e. poison species is generated during the electrooxidation. However, even as preface stated, isopropanol is the only molecule among $\mathrm{C}_{3}$ alcohol that does not dissociate into $\mathrm{CO}$ at the surface of platinum electrodes in acidic media. Fig.1 presents the cyclic voltammogram of isopropanol oxidation in alkaline media at an AT-cut quartz crystal Pt electrode. It is clear from Fig.1 that even in the potential region of hydrogen adsorption-desorption, isopropanol oxidation in the positive going potential sweep (PGPS) could take place immediately and produce two current peaks (I and II) at -0.56 and $-0.31 \mathrm{~V}$, which is similar to that of isopropanol oxidation in acidic media ${ }^{[1]}$. The results imply that there is no self-poisoning in the reaction, which is in accordance

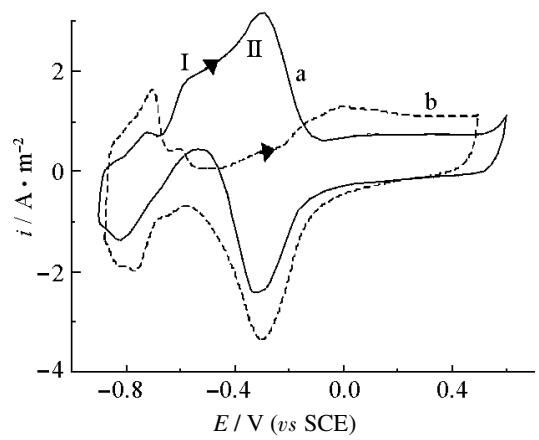

Fig.1 Cyclic voltamograms of Pt electrode in $0.1 \mathrm{~mol} \cdot \mathrm{L}^{-1}$

$\mathrm{CH}_{3} \mathrm{CHOHCH}_{3}+0.1 \mathrm{~mol} \cdot \mathrm{L}^{-1} \mathrm{NaOH}$ solution (a), $0.1 \mathrm{~mol} \cdot \mathrm{L}^{-1} \mathrm{NaOH}$ solution (b)

sweep rate $50 \mathrm{mV} \cdot \mathrm{s}^{-1}$ 
with in situ FTIR results (section 2.2). According to Li et al. ${ }^{[14]}$, the oxidation state of the Pt surface plays a key role in the oxidation of alcohols, the oxidation of alcohols on a Pt electrode is controlled by the formation of surface oxides on the Pt electrode at different potentials. The dependence of the reaction process on the oxidation states of the platinum surface yielded similar features in the cyclic voltammogram for oxidation of different alcohols at a Pt electrode, so it is difficult to assign two current peaks in PGPS. The branch of the $i-E$ curve in the negative going potential sweep(NGPS) is similar to that of other organic molecule oxidation $^{[1]}$ : only one oxidation current peak appears at $-0.51 \mathrm{~V}$, but its magnitude is very small, and another negative current peak, which is caused by the reduction of surface oxides formed at higher potentials in PGPS, is observed at $-0.31 \mathrm{~V}$.

\subsection{In situ FTIR results}

Fig.2 presents a series of spectra obtained by fixing $E_{\mathrm{R}}$ at $-0.90 \mathrm{~V}$, which is in the potential region of hydrogen adsorptiondesorption and is lower than the oxidation onset potential of isopropanol, and by varying $E_{\mathrm{S}}$ from -0.8 to $0.4 \mathrm{~V}$.

When $E_{\mathrm{S}}$ is lower than the threshold oxidation potential of isopropanol (near $-0.7 \mathrm{~V}$, see Fig.1) there are no significant features in the spectrum, but when $E_{\mathrm{S}}$ is at $-0.7 \mathrm{~V}$, a negative going band situated at $1699 \mathrm{~cm}^{-1}$ appears immediately. This feature coinc ides roughly with the oxidation onset potential of isopropanol. These spectra have the following features.

(a) In the range from 2100 to $1800 \mathrm{~cm}^{-1}$, no IR bands corresponding to adsorbed CO can be observed in Fig.2. This is a direct proof that isopropanol cannot dissociate into $\mathrm{CO}$ species during its interaction with the Pt surface, which is in accordance

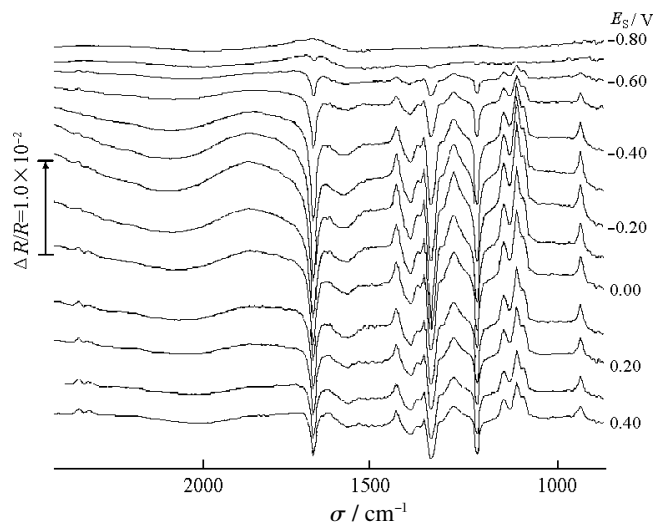

Fig.2 Difference spectra obtained with a Pt electrode in 0.1 $\mathrm{mol} \cdot \mathrm{L}^{-1}$ isopropanol $+0.1 \mathrm{~mol} \cdot \mathrm{L}^{-1} \mathrm{NaOH}$ solution The reference potential $E_{\mathrm{R}}$ was at $-0.90 \mathrm{~V}$, and the values of potential $E_{\mathrm{S}}$ for each spectrum are indicated in the figure. with the observation from cyclic voltammogram of Pt electrode in Fig.l. The similar situation has been reported in its oxidation on both Pt polycrystalline and single crystal electrode in acidic media $^{[-4]}$. In the isopropanol molecule, the $\mathrm{OH}$ group is connected to the second carbon atom of the chain, with a methyl at either side, so it may be too difficult for this carbon atom to approach the Pt surface for dissociation into CO.

(b) A few positive going bands near 947, 1127, 1116, 1166, $1468 \mathrm{~cm}^{-1}$ denotes the decrease of isopropanol concentration in the thin layer during the oxidation of isopropanol at $E_{\mathrm{s}}$.

(c) No negative going band corresponding to the $\mathrm{CO}_{2}$ asymmetrical stretch at $2340 \mathrm{~cm}^{-1}$ appears in the spectrum until $E_{\mathrm{S}}$ is at $0.4 \mathrm{~V}$, which indicates effectively that isopropanol is not oxidized into $\mathrm{CO}_{2}$ under present conditions ${ }^{[1]}$. This result differs from that reported in acid solutions, where isopropanol can easily be oxidized into $\mathrm{CO}_{2}{ }^{[1]}$.

(d) In the fingerprint region a few negative going bands may be seen on the spectra ${ }^{[1,15]}$. The bands near 1426 and $1369 \mathrm{~cm}^{-1}$ can be assigned to the the symmetrical and asym-metrical deformation of $\mathrm{C}-\mathrm{H}$ in the $-\mathrm{COCH}_{3}$ group respectively; the band near $1238 \mathrm{~cm}^{-1}$ can be attributed to the stretching plus bending of the $\mathrm{C}-\mathrm{CO}-\mathrm{C}$ chain; the band near $1699 \mathrm{~cm}^{-1}$ can be assigned to the $\mathrm{C}=\mathrm{O}$ stretching. It is worth pointing out that the intensity of these bands first increases steadily with the electrode potential to reach a maximum between $-0.30 \sim-0.10 \mathrm{~V}$, and then starts to decrease at more positive potentials.

(f) The baseline shift and the broad band which appears at $1600 \mathrm{~cm}^{-1}$ in the spectra of Fig. 2 as the electrode potential increases could be related to changes in the concentration of $\mathrm{H}^{+}$ and $\mathrm{OH}^{-}$in the thin layer as the reaction proceeds ${ }^{[16]}$. In fact, $\mathrm{H}^{+}$ is produced as isopropanol is oxidized, giving rise to change in $\mathrm{pH}$ which may be compensated by diffusion of $\mathrm{OH}^{-}$and $\mathrm{H}_{2} \mathrm{O}$ into the thin layer.

The combination of the above features indicates that under the experimental conditions, the main reaction occurring at the electrode is the dehydrogenation of isopropanol to acetone, i.e.

$$
\mathrm{CH}_{3} \mathrm{CHOHCH}_{3}+2 \mathrm{OH}^{-} \rightarrow \mathrm{CH}_{3} \mathrm{COCH}_{3}+2 \mathrm{H}_{2} \mathrm{O}+2 \mathrm{e}^{-}
$$

\subsection{EQCM results}

Fig.3 shows the $\Delta m$ variation in a solution containing 0.1 $\mathrm{mol} \cdot \mathrm{L}^{-1} \mathrm{CH}_{3} \mathrm{CHOHCH}_{3}$ and $0.1 \mathrm{~mol} \cdot \mathrm{L}^{-1} \mathrm{NaOH}$ measured with the AT-cut quartz crystal Pt electrode during the CV scanning. Nearly a constant value of $\Delta m$ is maintained from -0.90 to -0.78 $\mathrm{V}$ in PGPS. Compared with the isopropanol free electrolyte, 


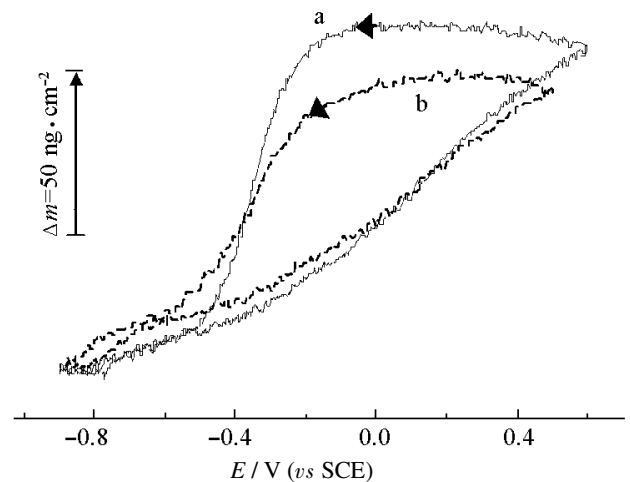

Fig.3 $\Delta m$ variation of $P t$ electrode in $0.1 \mathrm{~mol} \cdot \mathrm{L}^{-1}$ $\mathrm{CH}_{3} \mathrm{CHOHCH}_{3}+0.1 \mathrm{~mol} \cdot \mathrm{L}^{-1} \mathrm{NaOH}$ solution (a) and $0.1 \mathrm{~mol} \cdot \mathrm{L}^{-1} \mathrm{NaOH}$ solution (b)

sweep rate $50 \mathrm{mV} \cdot \mathrm{s}^{-1}$

where the $\Delta m$ increased continuously in the same potential region, this result may imply that isopropanol or its adsorptive products are possibly adsorbed preferentially on the electrode surface in this potential region ${ }^{[17-18]}$. Since no chemically adsorbed species are evidenced by in situ FTIR spectroscopy, this point cannot exclude the possibility of isopropanol and its dissociative adsorption on Pt surface, which indicates EQCM is a powerful tool for studying the interfacial electrochemical processes. From $-0.4 \mathrm{~V}$ on, the $\Delta m$ increases quickly, which is ascribed to the electrooxidation, re-adsorption of isopropanol and oxygen adsorption(or Pt surface oxidation). When $E$ varies from -0.4 to $0.6 \mathrm{~V}$, the $\Delta m$ increases by $87.9 \mathrm{ng} \cdot \mathrm{cm}^{-2}$. It is interesting to see that the $\Delta m$ almost remains constant between 0.6 and $-0.20 \mathrm{~V}$ in NGPS, then, it decreases quickly to joint the $\Delta m$ curve recorded in the PGPS when electrode potential is swept below $-0.20 \mathrm{~V}$, implying that the $\Delta m$ remains constant after one $\mathrm{CV}$ cycle.

\section{Conclusions}

The CV, EQCM and in situ FTIR spectroscopy are used to reveal the reaction mechanism of isopropanol oxidation in alkaline media on Pt electrode at a molecular level and quantitatively. The main conclusions can be drawn from the experimental results as follows:(1) there is no self-poisoning in the electrooxidation of isopropanol in alkaline media. (2) Since no chemically adsorbed species, such as CO, are evidenced by in situ FTIR spectroscopy, the adsorption of isopropanol or its dissociative products on $\mathrm{Pt}$ surface are suggested by EQCM data. (3) Isopropanol oxidation in PGPS could take place immediately even in the potential region of hydrogen adsorption-desorption, and two current peaks (I and II) at -0.56 and $-0.31 \mathrm{~V}$ are detected. (4) The final product of isopropanol oxidation is only acetone under the experimental condition, it may therefore be suggested that the oxidation of isopropanol into acetone takes place via dehydrogenation step. (5) The EQCM studies provide quantitative results of surface mass variation and have thrown new light in the elucidating isopropanol oxidation.

\section{References}

1 Sun, S. G.; Yang, D. F .; Tian, Z. W. J. Electroanal. Chem., 1990, 289: 177

2 Sun, S. G.; Lin,Y. J. Electroanal. Chem., 1994, 375: 401

3 Sun, S. G.; Lin,Y. Electrochim. Acta, 1996, 41: 693

4 Sun, S. G.; Lin,Y. Electrochim. Acta, 1998, 44: 1153

5 Horanyi, G.; Vertes, G.; Konig, P. Acta Chim. Acad. Sci. Hung., 1972, 72: 165

6 Horanyi, G.; Vertes, G.; Konig, P. Acta Chim. Acad. Sci. Hung., 1972, 72: 179

7 Pastor, E.; Iwasita, T. Extended abstracts of 44th ISE meeting. Berlin, 1993: 1.5.8

8 Lu, G. Q.; Sun, S. G.; Cai, L. R.; Chen, S. P. Langmuir, 2000, 16: 778

9 Santos, M. C.; Miwa, D. W.; Machado, S. A. S. Electrochemistry Communication, 2000, 2: 692

10 Parsons, R.; VanderNoot, T. J. Electroanal. Chem., 1988, 257: 9

11 Sun, S. G.; Chen, A. C. J. Electroanal. Chem., 1992, 323: 319

12 Lin, W. F.; Sun, S. G. Electrochim. Acta, 1996, 41: 803

13 Lin, H.; Chen, S. P.; Lin, J. M.; Chen, G. L. Electrochemistry, 2003, 19: 47

14 Li, N. H.; Sun, S. G.; Chen, S. P. J. Electroanal. Chem., 1997, 430: 57

15 Silverstein, R. M.; Bassler, G. C.; Morrill, T. C. Spetrometric identi fication of organic compounds. 4th ed. New York:Willy, 1986

16 Christensen, P. A.; Hamnett, A. J. Electranl.Chem., 1989, 260: 347

17 Gloaguen, F.; Leger, J. M.; Lamy, C. J. Electroanal. Chem., 1999, 467: 186

18 Shimazu, K.; Kita, H. J. Electroanal. Chem., 1992, 341: 361 


\title{
碱性介质中异丙醇在铂电极表面的吸附和电化学氧化
}

\author{
林 行 $^{1} \quad$ 陈国良 ${ }^{1,2} \quad$ 郑子山 $^{1}$ 周建章 ${ }^{2} \quad$ 陈声培 $^{2}$ 林仲华 ${ }^{2}$ \\ ( ${ }^{1}$ 漳州师范学院化学系, 福建 漳州 363000; 2 厦门大学化学化工学院, 固体表面物理化学国家重点实验室, 厦门 361005)
}

\begin{abstract}
摘要 运用电化学循环伏安、原位 FTIR 反射光谱和石英晶体微天平(EQCM)等方法研究了碱性介质中异丙 醇在 Pt 电极表面吸附和氧化行为. 结果表明: 碱性介质中异丙醇电氧化过程不存在自毒化现象. 虽然电化学 原位 FTIR 反射光谱未能检测到 CO 等毒性物种, 但 EQCM 结果证明异丙醇或其解离产物吸附于铂电极上. 在实验条件下, 碱性介质中异丙醇在铂电极上氧化的最终产物只有丙酮, 预示着碱性介质中异丙醇通过脱氢 步骤氧化成丙酮. EQCM 研究还从电极表面质量定量变化的角度提供了异丙醇吸附和电氧化反应机理的新 数据.
\end{abstract}

关键词：Pt 电极，电氧化，异丙醇，原位 FTIR， EQCM，碱性介质 中图分类号： O646.54, O433 